\title{
Abundância de liquidez e crise financeira em Roma: questões jurídicas e econômicas em torno das taxas de juros na época de Augusto e de Tibério ${ }^{1}$
}

Deivid Valério GAIA

\begin{abstract}
Resumo: Após ter vencido Antônio e Cleópatra na Batalha do Ácio em 31 a.C., Otaviano levou o tesouro dos reis do Egito a Roma, criando uma abundância de riquezas que contribui, consideravelmente, para estabilizar as finanças romanas, públicas e privadas, e que provocou a alta do preço da terra e a baixa das taxas de juros. Durante o Principado de Augusto, a economia romana conheceu um período de equilíbrio financeiro. No entanto, este equilíbrio foi rompido no início da década de 30 d.C. quando, de acordo com os relatos de Tácito, Suetônio e Dion Cássio, eclodiu a primeira crise financeira do Império Romano, crise de inopia nummorum (insuficiência de moedas em circulação), no Principado de Tibério. Partindo do estudo dos autores citados e de uma perspectiva comparativa com outras crises financeiras no Império romano, o meu objetivo neste artigo é de apresentar: na primeira parte, algumas considerações sobre as taxas de juros do fim da República ao Principado; na segunda parte, um quadro geral das questões dos empréstimos de dinheiro e das taxas de juros na época de Augusto; para, na terceira parte, propor uma nova leitura da crise de 33 d.C.
\end{abstract}

Palavras-chave: Inopia nummorum; Crise Financeira; Economia Romana; Império Romano; Taxas de Juros.

\footnotetext{
- Mestre em História e Antropologia da Antiguidade pela École des Hautes Études en Sciences Sociales, EHESS-PARIS (54, boulevard Raspail - 75006 PARIS). Doutorando do Centre Louis Gernet Recherches comparées sur les sociétés anciennes - École des Hautes Études en Sciences Sociales - EHESS - UMR8567. Membro do Laboratório de Estudos sobre o Império Romano (LEIR/ USP). E-mail: deivid.valeriogaia@ehess.fr
}

HISTÓRIA, São Paulo, 28 (2): 2009

571 


\section{Introdução}

A crise econômica perceptível em 2008-2009 afeta a economia mundial desde 2007, data na qual a maior parte dos países industrializados entraram em recessão por causa de uma crise financeira que começou a partir dos empréstimos imprudentes praticados nos Estados Unidos da América (existem inúmeras discussões sobre o início desta crise, não as citarei aqui). A crise do subprime provocou em 2007 perdas consideráveis que conduziram fortes tensões no mercado bancário. A situação financeira, que já estava muito delicada, piorou com o aumento dos preços do petróleo, matérias-primas e dos produtos agrícolas; ao mesmo tempo houve uma baixa dos preços dos imóveis e das ações. Em consequência de crédito fácil, de regulações e de supervisões inadequadas ou de ilegalidades crescentes, muitos bancos, tanto nos Estados Unidos da América quanto na Europa, tiveram de enfrentar grandes perdas. Diante da ameça de falência e de uma crise bancária sistemática, os Estados, ou seja, os poderes públicos, concederam ajudas massivas de vários tipos. Apesar das ajudas, houve uma recessão mundial que conduziu a uma redução do comércio, a alta do número de desemprego e a uma baixa dos preços dos produtos de base. Alguns chegaram a considerar esta crise como a pior depois da grande depressão ${ }^{2}$.

Esta crise financeira favoreceu a baixa do dólar e provocou o aumento das taxas de juros, que foram rapidamente reguladas pelos poderes públicos. Com a crise, o dinheiro e a liquidez se tornam cada vez mais raros, logo o dinheiro passa a custar mais caro e o resultado do aumento do valor do dinheiro provoca o aumento das taxas de juros. A crise financeira dos nossos tempos foi e é o foco das notícias jornalísticas dos últimos meses e chamou a atenção de todos, ou quase todos, pois, querendo ou não, quase todos sofrem os efeitos da crise, tanto os mais ricos quanto os mais pobres. Mas no caso de uma crise financeira, os ricos têm uma percepção mais clara da crise e suas decisões podem alterar o ritmo desta. 
Faço esta introdução, não porque eu queira estudar a crise financeira de uma sociedade industrializada como a nossa, pois, para mim, o historiador não precisa e não deve assinar nenhum contrato de responsabilidade com o que se passa hoje. Embora às vezes pareça inevitável, não menciono aqui as experências do historiador com o seu cotidiano, pois destas ninguém se livra, mas me refiro à escrita de uma história militante, uma história "prática" para se entender o presente. No meu caso, o fato de ter uma crise financeira agora, pode levar o leitor a fazer comparações, mas para evitar qualquer tipo de anacronismo, prefiro não me posicionar, neste estágio da pesquisa, numa análise comparativa entre as crises de ontem e de hoje. Prefiro, ao contrário, comparar as crises das sociedades pré-industriais entre si. Mas é o contexto presente que me inspira e me leva a perguntar, como eram as crises financeiras e monetárias nas sociedades pré-industriais? Talvez a pergunta possa parecer muito elementar e ao mesmo tempo vasta. Então, proponho guardá-la como pano de fundo e aprofundar a análise sobre a abundância de circulação monetária após a batalha do Ácio e sobre uma crise, a primeira crise financeira e monetária de uma economia globalizada como aquela do Império Romano, a saber, a crise de inopia nummorum, de 33 d.C. que ocorreu no Principado do Imperador Tibério. Partindo do estudo de autores como Tácito, Suetônio e Dion Cássio, e de uma perspectiva comparativa com outras crises financeiras do Mediterrâno romano, o meu objetivo neste artigo é de apresentar; na primeira parte, algumas considerações sobre as taxas de juros do fim da República ao Principado; na segunda parte, um quadro geral das questões dos empréstimos de dinheiro e das taxas de juros na época de Augusto; para, na terceira parte, apresentar a minha leitura da crise de 33 d.C., destacando as discussões principais em torno de suas origens, de seu desenvolvimento e de seu fim. 


\section{Balanço geral sobre as taxas de juros no fim da República e no Principado}

As taxas de juros foram, durante a época republicana e imperial, um dos problemas que mais preocuparam os poderes públicos, sobretudo em caso de crise. Quando surgia um problema ligado às dividas e à alta das taxas de juros, reclamava-se uma interferência legal através da criação de leis ou de medidas contra as taxas de juros abusivas. A decisão tomada era, na maioria dos casos, a de limitar os juros às mesmas taxas que foram estabelecidas no início do empréstimo ${ }^{3}$.

Para analisar esta preocupação dos poderes públicos com relação às dívidas, é importante perguntar: existiam limites para as taxas de juros na República e no Principado? É evidente, segundo a documentação, que as províncias desta época fixavam de modo geral limites para as taxas de juros. Desde o fim da República e durante o Principado, o limite das taxas de juros era de $12 \%$ por ano, ou seja, 1\% por mês, em latim centesimae usurae (o emprego generalizado da expressão no plural se explica pela variedade dos meses em que se dá o pagamento do empréstimo). No fim da República, conhecemos três exemplos deste tipo: 1) O edito provincial de Cícero na Cilícia em 51-50 a.C., que limitou as taxas de juros a $12 \%$ por $\left.\mathrm{ano}^{4}, 2\right)$ As decisões de Luculos na Ásia que também limitou as taxas de juros a $12 \%$ por $a^{5} o^{5}, 3$ ) e por fim, no ano de 51 a.C., o senado fixou as taxas de juros máximas a $12 \%{ }^{6}$. Se esta limitação formulada pelo Senado em 51 a.C. foi ou não confirmada por César e por Augusto, nós não sabemos.

As taxas de juros praticadas, tirando algumas exceções, variavam entre 4 e $12 \%$ ao ano. Cícero evidencia que em 55-54 a.C., era possível emprestar dinheiro em Roma a $4 \%^{7}$. Suetônio menciona que as taxas juros eram de 4\%, devido à entrada dos tesouros dos reis do Egito em Roma após a batalha do Ácio, em 31 a.C. ${ }^{8}$. É muito difícil encontrar referências a taxas de juros abaixo de $4 \%$ nas fontes disponíveis. Um raro exemplo se encontra no Digesto, que menciona uma taxa de juros de $3 \%$ ao 
ano. Há também outro texto do Digesto que menciona usurae unciae, ou seja, de $1 \%$ ao ano. Como o valor é anormalmente baixo, é possível que tal taxa seja mencionada pela sua representação simbólica e filantrópica ${ }^{9}$. Um dos autores da História Augusta qualifica a taxa de juros de $4 \%$ de minimae usurae $^{10}$, quando escreve que Antonino Pio emprestava dinheiro a esta taxa ${ }^{11}$. As taxas de juros de $6 \%$, cujo uso parece corrente sob o Principado, são consideradas por Plínio, o Antigo, como uma taxa módica e legal "ex his tamen usura multiplicata semissibus, quae ciuilis ac modica est ${ }^{12}$ ".

No que diz respeito às altas taxas de juros, constata-se que, fora os casos claramente abusivos, a taxa de 12\% não era quase nunca ultrapassada segundo a documentação literária e jurídica. Havia, com certeza, taxas de juros abusivas camufladas nos contratos de empréstimos dos banqueiros e dos financiadores profissionais, mas é difícil estudar estas operações por causa da falta de documentação quantitativa, que nos permitiria identificar padrões claros nestas ações à margem da lei. Contudo, há uma fundação evergética que parece indicar uma taxa estranhamente elevada de $15 \%{ }^{13}$. Quando se tem notícia de juros ultrapassando os $12 \%$, as fontes mencionam taxas bem mais altas, que vão diretamente a 24,48 ou mesmo a $60 \%{ }^{14}$.

Sendo assim, será que havia uma limitação geral? Andreau responde: "C'est très possible; ce n'est pas absolument certain ${ }^{15}$ ". Giuseppe Camodeca ${ }^{16}$ e Koenraad Verboven ${ }^{17}$ defendem que sim. Seja como for, tanto é certo que durante o Principado o empréstimo a juros nunca foi proibido, quanto que raríssimas fontes apresentam taxas de juros superiores a $12 \%$. O Estado romano tem a tendência de fixar taxas de juros máximas, mas nem por isso são taxas de base. Trata-se apenas de um teto, e é entre o piso e o teto que estas taxas variam, exceto, evidentemente, as taxas de juros abusivas, hoje conhecidas como usura ${ }^{18}$. Para o mundo romano a taxa de juro abusiva (magna usura, grauissima usura, maxima usura, etc), não aparece claramente nos contratos e nos documentos literários ${ }^{19}$, visto que era totalmente proibida. 
Segundo a documentação disponível (a qual, aliás, se deve à elite), sob o Principado, as taxas de juros eram limitadas a $12 \%$ em algumas províncias, como por exemplo no Egito, onde a taxa de juro máxima era sempre de $12 \%$. Segundo Gustav Billeter e Maurice Sartre, os juros eram mais baixos na Itália e no Mediterrâneo ocidental (4 a 6\%) e mais elevados na parte grega do Império (8 a $9 \%$ ), sobretudo no Egito $(12 \%)^{20}$.

A política administrativa do governador da província tinha um papel fundamental nas relações financeiras. Com efeito, um dos deveres dos poderes públicos na época imperial era de assegurar a tranquilidade no conjunto do Império. Era necessário, para evitar revoltas, regulamentar a questão das taxas de juros. Alguns fragmentos do Digesto mostram com mais clareza as limitações das taxas de juros pelos poderes públicos. Os jurisconsultos mencionam o legitimus modus usurarum (limite da taxa de juro fixada por lei) ou as legitimae usurae (juros fixados por lei) ${ }^{21}$. Estes textos mostram que as legitimae usurae fazem parte da tradição comum de certas áreas, já que se referem a regiões específicas (infelizmente, os nomes de tais regiões não são citados).

É necessário observar que outros textos do Digesto mencionam alguns costumes regionais e que as variações das taxas de juros também podem estar ligadas aos costumes de cada região. Costume que, vale lembrar, se mostra durável e revela a necessidade de levar em conta as tradições locais ou regionais para o estudo das taxas de juros no mundo romano ${ }^{22}$. $\mathrm{O}$ legitimus modus usurarum talvez seja característico de uma região ou de muitas regiões, mas de forma alguma válido para o conjunto do Império ${ }^{23}$.

Para a Itália, no fim da República, conhecem-se casos de variações bruscas e frequentes. Em compensação, no Principado, as poucas fontes disponíveis não mencionam grandes variações. As taxas citadas são, de modo geral, baixas, amiúde entre 4 a $6 \%$ ao ano, devido à estabilidade financeira desta época. Estas taxas são confirmadas pela grande maioria das inscrições das fundações evergéticas ${ }^{24}$ que estão distribuídas em diversas partes do Império Ocidental. 
ABUNDANCIA DE LIQUIDEZ E CRISE FINANCEIRA EM ROMA:...

\section{Uma ruptura com os maus tempos da República romana : a Batalha de Ácio e uma nova circulação monetária}

No início do Principado romano, houve uma grande transformação com relação às atividades financeiras privadas, e o marco destas mudanças foram os eventos que se seguiram à Batalha do Ácio. Dion Cássio ${ }^{25}$ e Suetônio ${ }^{26}$ deixaram-nos testemunhos para compreender o estado das taxas de juros nesse período de transição entre os últimos agitados anos da República e o Principado de Augusto.

Os testemunhos desses dois autores sobre as taxas de juros representam um importante testemunho para o estudo das variações destas, pois são os primeiros a informar sobre uma baixa e uma estabilização neste período de transição política, e é a partir deste momento que Roma viverá uma época de relativo equilíbrio no que concerne à vida financeira até a grande inflação do século III d.C. Os autores mostram que após a Batalha do Ácio, o tesouro dos reis do Egito foi levado a Roma. Uma parte foi transformado em moedas e estas foram colocadas em circulação (nam et inuecta urbi Alexandrino triumpho regia gaza tantam copiam nummariae rei effecit $^{27}$ ).

Com grande quantidade de dinheiro circulando, houve, segundo Dion Cássio, uma baixa das taxas de juros de 12 para $4 \%$ e uma alta dos preços dos imóveis

TOбоÛTov үà

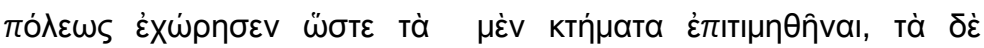

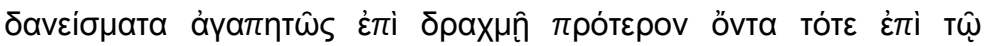

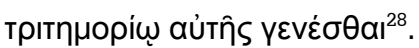

Ou seja, os juros passam do seu mais alto nível de costume (que era legal), ao seu nível mais baixo, e o mais importante é que o preço baixo dos juros se manterá durante muito tempo. Suetônio também escreve que os juros diminuíram, mas não é tão claro quanto Dion Cássio. De acordo com Marie-Laure Freyburger, 
Dion é mais preciso do que Suetônio, pois se trata de um tema que o interessa mais particularmente ${ }^{29}$.

A riqueza dessas duas passagens reside, sobretudo, no fato de que tal circulação monetária colocou fim às instabilidades financeiras do fim da República, onde as taxas de juros abaixavam e subiam constantemente de forma brusca. Sabe-se, por exemplo, que antes da entrada do tesouro dos reis do Egito, as taxas de juros eram de 12\%, mas com a circulação monetária intensa da época de Augusto, as taxas de juros baixam (minimae usurae). Esta maior circulação monetária, além de provocar a baixa dos juros, provocou, como mostra Suetônio, a alta do preço da terra. Daí pode-se pensar no preço da terra e no preço do dinheiro como se estivessem em uma gangorra, um variando em função do outro - por isto se procurava o equilíbrio. "ut faenore deminuto plurimum agrorum pretiis accesserit $t^{30 " .}$

Observa-se também, a partir da análise do texto de Suetônio, que Augusto, para manter a circulação da moeda sempre ativa, uma vez que havia uma abundância de moedas no tesouro público (abundância vinda das confiscações), emprestava dinheiro sem juros para aqueles que podiam dar o dobro da quantia emprestada como caução : "et postea, quotiens ex damnatorum bonis pecunia superflueret, usum eius gratuitum iis, qui cauere in duplum possent, ad certum tempus indulsit". Com esta iniciativa, Augusto alimentou o mercado do crédito e contribuiu para uma circulação monetária, o que evitou uma crise de falta de liquidez (inopia nummorum), como aconteceu em 64-63 a.C. em 49 a.C. ${ }^{31}$ e no Principado de Tibério, como veremos a seguir. Mas se Augusto emprestava dinheiro sem juros para aqueles que tinham o dobro da caução, acredito que os feneratores ${ }^{32}$ tinham uma clientela bem reduzida nesta época. Talvez eles emprestassem dinheiro com mais abundância nas épocas em que havia menos confiscações, ou sobrassem para os feneratores (nos momentos em que Augusto emprestava dinheiro gratuitamente) os clientes que não tinham o dobro da caução. Emprestavam dinheiro para os mais endividados, alimentando com isto o mercado ilegal do dinheiro, com altas taxas de juros que, justamente pelo seu caráter ilegal, não temos 
ABUNDANCIA DE LIQUIDEZ E CRISE FINANCEIRA EM ROMA:...

fontes. Talvez o fato de Augusto emprestar dinheiro a título gratuito e promover uma maior circulação monetária, ajude a pensar na censura que ele mesmo formulou contra os cavaleiros que faziam empréstimos a baixos juros para emprestarem a taxas abusivas ${ }^{33}$.

Depois da entrada do tesouro egípcio, Roma conheceu um período de tranquilidade para as relações financeiras, colocando fim aos tempos agitados da República. Esta tranquilidade financeira perdurou até o século III d.C. No entanto, houve algumas instabilidades do início do Principado (I século a.C.) à inflação do século III d.C. Apresentarei aqui uma destas instabilidades, a crise de inopia nummorum na época no Imperador Tibério, a que, para facilitar a compreensão, chamamos de crise de 33 d.C., embora a crise tenha começado muito antes.

\section{Inopia nummorum: uma leitura da crise de 33 d.C.}

A crise de 33 foi muito estudada e houve conclusões diversas acerca do episódio. Deixando de lado as minúcias de um debate tão acirrado, prefiro centrar minha análise sobre o estado das taxas de juros e suas relações com o preço da terra nesse contexto de crise econômica e social. Tácito, Suetônio e Dion Cássio evocaram esse período de perturbações econômicas num contexto político tenso, marcado, para citar dois exemplos, pelas questões em torno de Sejano e pelas manifestações populares contra a alta do preço do trigo. A narrativa mais completa, mesmo que muito confusa e de interpretação delicada, é a de Tácito ${ }^{34}$. Suetônio ${ }^{35}$ escreve pouco sobre a crise, e Dion Cássio ${ }^{36}$ apresenta a crise somente para falar do suicídio de Nerva, senador e amigo de Tibério. É importante saber que esta crise, apesar dos problemas de interpretação e da falta de fontes, é uma das mais bem documentadas.

Tácito apresenta rapidamente, no início de seu texto, o histórico dos problemas causados pelos empréstimos a juros no início da República romana. Escreve que, em 33 d.C ${ }^{37}$, uma 
grande massa de acusadores ${ }^{38}$ se precipitou sobre aqueles que faziam frutificar suas fortunas por meio do empréstimo a juros ${ }^{39} \mathrm{e}$ havia muitas queixas diante do pretor Graco contra estes (feneratores). Segundo as acusações, os credores não respeitavam uma antiga lei de Júlio César de modo credendi possidendique intra Italiam $^{40}$, lei que não era aplicada desde há muito tempo. Esta lei fixava o limite do crédito e das possessões na Itália.

Será que esta lei fixava o limite das taxas de juros? Esta questão não pode ser respondida facilmente, pois não temos ricas informações sobre a mesma. Os especialistas Gustav Billeter ${ }^{41}$ e Jean Andreau, alemão e francês respectivamente, sobre as taxas de juros na antiguidade, não acreditam que a lei cesariana de modo credendi possidendique intra Italiam tenha limitado as taxas de juros. No entanto, Andreau não rejeita a possibilidade de que outra medida de César, da qual não nos resta vestígios, o tenha feito ${ }^{42}$. Com outra opinião, Claude Nicolet escreve que, sobre a lei em questão, seja qual fossem seus objetivos, um deles era limitar as taxas de juros ${ }^{43}$. Ségolène Demougin também acredita que esta lei limitava as taxas de juros $^{44}$.

De acordo com Tácito, esta lei foi neglicenciada durante muito tempo, porque os interesses privados passaram na frente dos interesses públicos. O pretor Graco, incumbido de resolver esta questão (as queixas dos acusadores), foi obrigado, pelo tão grande número de acusações, a levar esta causa ao Senado (multitudine periclitantium subactus rettulit ad senatum). Os membros do Senado, ao conhecer a situação de forma oficial (com certeza já conheciam o problema), ficaram inquietos (trepidique patres), pois, como escreve Tácito, ninguém se livrava de tal culpa ${ }^{45}$, já que os senadores também faziam frutificar suas fortunas pelo empréstimo a juros. O senado com medo, pediu ajuda ao Príncipe e Tibério lhes concedeu dezoito meses para que cada um colocasse seus negócios em ordem.

Ségolène Demougin defende que, de fato, a maioria dos senadores, a despeito das interdições legais ${ }^{46}$, emprestavam dinheiro a juros e temiam então sofrer com os rigores desta $l \mathrm{i}^{47}$, 
ABUNDANCIA DE LIQUIDEZ E CRISE FINANCEIRA EM ROMA:...

ou seja, o restabelecimento da lei de César sobre o limite do crédito e das possessões. A medida de Tibério de lhes conceder dezoito meses mostra que a crise já havia eclodido. $\mathrm{E}$ quando a crise começou?

Para Nicolet, inicialmente, a simples aplicação da lei limitando as taxas de juros e dando aos devedores ${ }^{48}$ dezoito meses para colocarem as coisas em ordem, foi seguida de uma falta de liquidez, inopia rei nummariae, a causa e o efeito concomitantes foi uma baixa de preço das terras e a alta das taxas de juro ${ }^{49}$. Jean Andreau argumenta que a crise de inopia nummorum foi provocada pelos esforços de Tibério de colocar em vigor a lei de César ${ }^{50}$. Segundo André Tchernia, os tempos de crise se distribuem da seguinte forma: retomada em vigor da lei de César; os credores pedem que as dívidas sejam pagas; crise de inopia nummorum; senatus-consulto com a tentativa de remediar a crise; agravamento da crise e, por fim, os empréstimos gratuitos de Tibério ${ }^{51}$. Ou seja, para esses autores, a crise começa com o restabelecimento da lei de César.

No entanto, em minha opinião, a crise não começou quando a lei de César foi recolocada em vigor, como defendem Claude Nicolet, Jean Andreau, André Tchernia e outros. Parece-me que a crise tem seu início muito antes, com as confiscações do Estado que entesourava o dinheiro das vendas dos bens dos condenados. O Principado de Tibério foi marcado por confiscações em grande número. Com elas, o entesouramento aumentava. O quadro foi agravado a partir de 16 de outubro de 31, quando Sejano foi executado. Os seus cúmplices tiveram os seus bens confiscados, e a venda dos bens aumentou a quantidade de moeda nos cofres imperial e público (signatum argentum fisco vel aerario attinebatur.). Ao invés de emprestar o dinheiro sem juros para aumentar a circulação monetária, como fez Augusto ${ }^{52}$, Tibério entesourou este dinheiro. Se pensarmos na quantidade de dinheiro que já vinha sendo entesourado desde 24 d.C., isto aumenta mais as possibilidades de que a inopia nummorum já existente só tenha se intensificado em 33 d.C. (quando os feneratores foram acusados). A intensificação da crise, contudo, não marca o seu início ${ }^{53}$. Tanto Tácito quanto 
Dion Cássio escrevem sobre o expressivo volume de confiscações e sobre a queda do preço da terra provocada por tal procedimento.

Além das confiscações e do entesouramento, têm-se também todas as discussões a respeito da diminuição da cunhagem de moeda na época de Tibério. Tenney Frank afirma que Tibério, antes de 33 d.C., tinha cunhado poucas moedas e ao mesmo tempo gastava pouco ${ }^{54}$. No entanto, C. Rodewald escreve sobre a importância da cunhagem de bronze na década de 20 d.C ${ }^{55}$. Jean Andreau conclui que essas teses são discutíveis e que Tibério não foi seguramente um imperador esbanjador (como mostrei acima), mas que seria mais interessante pensar em termos da vivacidade das transações monetárias e não somente no estoque monetário. No entanto, a concentração do estoque monetário, em 33 d.C., acentuou a falta de moedas ${ }^{56}$. C. Rodewald apresenta os problemas das teses de Frank e apresenta uma importante cunhagem durante a década de 20 d. $\mathrm{C}^{57}$.

Além desse primeiro entesouramento que foi o resultado das vendas das terras confiscadas, há um segundo entesouramento, que acorreu quando o senatus-consulto prescreveu que os credores (feneratores) deveriam investir dois terços de suas somas em terras situadas na Itália (tanto Tácito quanto Suetônio escrevem sobre isto), a pedido de Tibério ou do Senado $^{58}$. O restabelecimento da lei de César ocorreu em 33 d.C., foi em resposta às acusações feitas ao pretor Graco, levadas ao Senado e em seguida levadas ao Imperador, pois, como os acusadores se precipitavam sobre os credores que não respeitavam mais a lei de César, Tibério resolveu recolocá-la em vigor, talvez pensando que isto resolveria a crise. Por isto que Tácito escreve que o Senado prescreveu que os feneratores deveriam investir dois terços do dinheiro em terras italianas ${ }^{59}$. Adoto a mesma postura de Claude Nicolet, defendendo que o senatus-consulto mencionado por Suetônio e por Tácito estava colocando em vigor a lei de César $^{60}$, visto que a lei é citada ordenadamente no texto de Tácito. No início e no fim de cada parágrafo, ele se refere sempre à mesma lei ${ }^{61}$. 
ABUNDANCIA DE LIQUIDEZ E CRISE FINANCEIRA EM ROMA:...

Se pensarmos em uma lógica econômica e compararmos esta crise com outras do Império Romano, essa medida visava evitar uma queda brutal dos preços das terras, visto que, num contexto de crise, se observa constantemente a queda dos preços das terras e a alta das taxas de juros. Se os preços das terras abaixassem, os devedores veriam agravadas suas incapacidades de saldar as somas devidas, pois grande parte dos devedores eram proprietários (logo mais tratarei a questão do estatuto social dos endividados). O retorno, em 33 d.C., da aplicação desta lei solidifica a hipótese de que Roma atravessava um período de crise com alta taxas de juros, o que indica que a crise não começou em 33 d.C., quando houve as acusações.

Por que acima falei de um segundo entesouramento? Em minha opinião, a tentativa de reorganização proposta pelo senatus-consulto ou por Tibério, restabelecendo esta lei, não contribuiu para o fim da crise. Pelo contrário, foi um dos maiores fatores para o seu recrudescimento. Este proceder só piorou a crise de inopia nummorum, porque agora temos dois tipos de entesouramento, aquele do Estado, vindo das confiscações, e outro dos feneratores que deveriam economizar para comprar terras na Itália. O próprio Suetônio escreve que tal medida não foi suficiente para remediar a crise (nec res expediretur). Para Claude Nicolet, a aplicação de medidas antigas, que talvez tenham sido suficientes para remediar parcialmente a crise de 49 - 45 a.C., mostraram-se insuficientes em 33 d.C., visto que o contexto de crise não era o mesmo ${ }^{62}$.

Como os faeneratores foram constrangidos a comprar tais terras, pediram aos seus devedores que as dívidas fossem pagas. Talvez tenham feito isto para deixarem os devedores em má situação, já que estes os acusavam ou tenham realmente pedido o dinheiro das dívidas porque deveriam comprar as terras como prescreveu o Senado. Talvez também pudessem estar aproveitando o preço baixo das terras para comprá-las. Não se pode saber a real causa, por isto me limito a construir hipóteses apenas sobre os motivos mais específicos do aprofundamento da crise. Segundo Tácito, não era conveniente 
por parte dos devedores deixar de pagar as dívidas, porque ficariam sem credibilidade (nec decorum appellatis minuere fides). No desespero, os devedores recorreram a todos os trâmites possíveis. Depois pediram socorro ao próprio pretor, Graco, que recebeu as acusações.

Em virtude dos pedidos dos devedores, os meios empregados pelo pretor como primeiro remédio à crise, segundo Tácito, foram a venda e a compra (vendito et emptio). No entanto, estes meios não foram suficientes, porque os feneratores, aqueles que podiam comprar, já economizavam suas fortunas para comprarem as terras italianas, como pediu o Senado (in contrarium mutari quia faeneratores omnem pecuniam mercandis agris condiderant). Neste momento de pouca circulação monetária, seja qual fosse a situação, segundo Tácito, o dinheiro estava nas mãos dos feneratores e entesourado nos cofres imperial e público. Tem-se aí, realmente, uma grande crise de crédito, falta de circulação quase total e desaparecimento dos agentes financeiros privados do mercado.

Neste contexto, a procura por moeda era maior do que a oferta. Os preços das terras caíram rapidamente (já vinham caindo desde o início das confiscações), uma vez que a medida do Senado não resultou de imediato em opções de compra. Ao contrário, resultou na retirada de moeda de forma geral, servindo para reduzir drasticamente a liquidez. Isto agravou a alta das taxas de juros, que já vinham subindo desde o momento em que os bens dos condenados foram vendidos e entesourados por decisão do princeps. Com o primeiro entesouramento Estatal, iniciou-se a crise de inopia nummorum, com o segundo entesouramento, promovido pelos feneratores, a crise de inopia nummorum foi largamente agravada.

André Techernia, baseando-se na teoria de Adam Smith, mostra, no seu artigo intitulado "Remarques sur la crise de 33" que, numa sociedade principalmente agrícola, o preço da terra e o nível das taxas de juros são indissociáveis, um varia em função do outro. Se as taxas de juros sobem, as terras serão vendidas para produzir capital a fim de que as dívidas sejam pagas ${ }^{63}$.

Talvez isto explique porque muitos romanos praticavam os 
ABUNDANCIA DE LIQUIDEZ E CRISE FINANCEIRA EM ROMA:...

dois tipos de investimentos (a terra e o empréstimo a juros). Sabe-se que era usual aos membros da elite romana terem, além da propriedade fundiária, dinheiro emprestado a juros (geralmente por meio dos libertos e escravos). Este comportamento econômico deriva do seguinte fato: no caso de uma crise financeira, a terra perde parte do seu valor e os juros passam a ser o rendimento mais alto. A elite fundiária, conhecedora deste mecanismo, defende-se, resolvendo também emprestar a juros. Mas isso não quer dizer que todos emprestavam a juros.

Tácito destaca que quanto mais as pessoas estavam endividadas, mais tinham dificuldades de vender seus bens e tinham que aceitar os preços ruins do mercado. Por isso muitos viam as suas fortunas se acabarem e a ruína do patrimônio tinha como consequência a perda do prestígio e da reputação (copiam vendendi secuta vilitate, quanto quis obaeratior, aegrius distrahebant, multique fortunis provolvebantur). Tocava-se assim em uma ferida da sociedade romana: o problema maior não é somente perder a fortuna, mas, sim, o tão almejado e valorizado prestígio. Havia uma exposição pública de muitos membros da elite, pois quando viam que seus bens não eram tão valorizados, se sentiam humilhados, em muitos casos o valor da dívida excedia o valor dos bens. Isto confirma que estes devedores não eram nada pobres, o que não impede, sem dúvida, o fato de existirem pobres endividados.

Vistas as desordens econômica, política e social, Tibério entra em cena novamente. Para acabar de vez com a crise e restituir a ordem, veio ao socorro dos cidadãos romanos endividados. Injetou no mercado do crédito cem milhões de sestércios sine usuris, ou seja, a título gratuito. Emprestou dinheiro com um prazo de três anos, por intermédio dos escritórios financeiros (Tácito escreve por meio de mensae ${ }^{64}$ ), dirigidos por alguns senadores ${ }^{65}$. Assim como fez seu antecessor, Augusto, Tibério emprestou dinheiro à condição de que o devedor fornecesse garantias de caução em terras equivalente ao dobro da soma emprestada ${ }^{66}$. Para pagar as dívidas, eles não tinham, a partir de então, necessidade de se desfazer dos seus 
patrimônios.

Segundo Tácito, com esta decisão, Tibério remediou a crise de inopia nummorum e a fides (neste sentido equivale a crédito / confiança), foi restabelecida. Pouco a pouco, era possível encontrar dinheiro a ser emprestado, mesmo entre os particulares. Já quanto à lei referente à compra de terras, esta foi deixada por laxismo . sic refecta fides et paulatim privati quoque creditores reperti. neque emptio agrorum exercita ad formam senatus consulti, acribus, ut ferme talia, initiis, incurioso fine.

Dion Cássio vai ao encontro de Tácito, escrevendo que Tibério deu ao tesouro público 20 milhões de dracmas (cem milhões de sestércios se contarmos que 1 dracma equivalha a 5 sestércios) para que os senadores emprestassem dinheiro sem juros por três anos, a quem eles quisessem. Dion destaca que os senadores emprestavam o dinheiro a quem eles queriam. Talvez com isto ele queira denunciar o mau proceder dos senadores da época. Com o fim da crise, Dion Cássio acrescenta que Tibério pediu para que fossem assassinados em um só dia os mais barulhentos dos acusadores ${ }^{67}$.

Esta crise oferece exemplos de empréstimos a longo prazo (como o de Tibério) e coloca em foco o papel dos intermediários na economia romana. No entanto, qual era a taxa de juros dos empréstimos nesta época de crise, levando em conta que a crise começou bem antes de 33 d.C.? De 24 a 31 as taxas de juros deveriam aumentar gradativamente de acordo com 0 entesouramento imperial. Após a execução de Sejano até o momento em que houve as acusações, as taxas de juros deveriam estar ainda mais altas. Caso contrário, Tácito não começaria seu texto escrevendo sobre os problemas que o empréstimo a juros causou na Urbs durante a República romana. Já em 33 d.C., no auge e no fim da crise, não se pode mais falar em aumento das taxas de juros, pois neste momento tem-se o desaparecimento dos agentes financeiros do mercado e com eles tem-se o desaparecimento do empréstimo de dinheiro a juros. Se houve empréstimos a juros, eram mínimos e ligados à relação de amicitia. Não temos nenhuma fonte que faça menção à tal 
procedimento. Ao fazer um estudo comparativo entre as crises financeiras na época republicana, sabe-se que desde que há um entesouramento, há uma falta de liquidez, há uma diminuição do preço das terras, por isso tem-se a alta das taxas de juros. Mas quando uma crise toma as proporções que a crise financeira da época de Tibério tomou em 33 d.C., tem-se o desaparecimento dos agentes financeiros e só retornam com a intervenção dos poderes públicos, que colocam mais moedas em circulação, permitindo, assim, o retorno da fides.

A diminuição da quantidade de dinheiro disponível para o empréstimo, a queda dos preços da terra e os riscos assumidos pelo emprestador neste período de crise provocaram, invariavelmente, uma alta nas taxas de juros que vinha antes de 33 d.C.. Após o restabelecimento da lei de César pelo senatusconsulto, tem-se a desaparecimento dos agentes financeiros. Mas desde que o crédito foi pouco a pouco recuperado, era possível encontrar mesmo particulares para emprestar dinheiro a juros baixos.

\section{Conclusão}

Depois da entrada do tesouro egípcio, após a Batalha do Ácio, Roma conheceu um período de tranquilidade para as relações financeiras, colocando fim aos tempos agitados da República. Esta tranquilidade financeira perdurou até o século III d.C. Houve algumas instabilidades do início do Principado (I século a.C.) à inflação do século III d.C., como, particularmente, a crise financeira na época de Tibério.

Concluo com relação a esta última que o texto de Tácito é o mais rico para conhecê-la. No entanto, a ordem do texto não explica a ordem dos acontecimentos, pois o texto é muito confuso. Mas é a partir de uma análise comparativa do texto de Tácito com outros textos, comparativa também no sentido temporal, ou seja, estudando outras crises financeiras em Roma, que se pode entender o texto com mais clareza. 
A partir do exemplo da entrada dos tesouros egípcios em Roma desde a crise na época de Tibério, pode-se ver claramente a importância da circulação monetária para a saúde da economia e que a falta de circulação de moedas boqueia o "mercado" do crédito. É nesse sentido que a frase de Jean Andreau se reveste de toda sua significação ${ }^{68}$ "Le mécanisme se grippait dès qu'il y avait une crise des paiements ou une crise d'endettement." A medida de Tibério funda-se (explicitamente ou não) sobre esta constatação, uma vez que o bloqueio deste "mercado" trouxe graves problemas para a ordem imperial. Tácito observa que a crise acabou quando as atividades de empréstimo se reiniciaram, ou seja, quando houve novamente uma circulação monetária.

Defendo que a crise da época de Tibério se desenvolveu da seguinte forma: confiscações; entesouramento; alta das taxas de juros; baixa do preço da terra; acusações contra os feneratores, porque estes não respeitavam a lei de César; aplicação da lei; os feneratores economizam suas fortunas para comprarem as terras; os feneratores pedem para que dívidas sejam pagas; tem-se aí uma crise geral, que leva os endividados a perder o patrimônio, o prestígio e a reputação; com isto houve a intervenção imperial com o empréstimo sem juros; nova circulação monetária; fim da crise e, enfim, o reaparecimentos dos agentes financeiros.

A partir dos testemunhos de Tácito, de Suetônio e de Dion Cássio sobre a entrada dos tesouros egípcios em Roma e sobre a crise de inopia nummorum, vê-se que as taxas de juros aumentam consideravelmente quando há uma penúria de moedas e que também há uma baixa do valor da terra (viceversa). Sendo assim, o valor dos bens fundiários, o nível das taxas de juros e a rarefação da moeda eram indissociáveis. Nestas condições, uma crise econômica no Império romano pode ser ao mesmo tempo monetária, financeira e fundiária e só pode ser resolvida pela intervenção do poder imperial.

As ligações entre circulação monetária, sua concentração e sua dilatação, as taxas de juros e o preço das terras parecem claramente estabelecidos se compararmos a crise de 49-45 a.C., com a crise de 33 d.C e levarmos em conta a entrada dos 
ABUNDANCIA DE LIQUIDEZ E CRISE FINANCEIRA EM ROMA:...

tesouros egípcios em Roma. Acredito que, para chegar em resultados melhores, é necessário colocar vários momentos de abundância e de penúria monetária em comparação, não somente comparar diferentes períodos da história romana entre si, mas comparar a economia da sociedade romana com a economia de sociedades pré-industriais. Pois, tendo em vista a falta de fontes, uma análise prudente e comparativa seria profícua para o estudo da economia e, sobretudo, das crises financeiras no mundo antigo. Tenho este objetivo como uma das metas principais a serem desenvolvidas em minha tese de doutorado.

\title{
Agradecimentos
}

Agradeço com muita alegria a meus amigos e colegas pelas críticas ao texto e pelo incentivo. Agradeço aos meus mestres pela constante presença, conselhos e críticas: Jean Andreau, Jean-Michel e Norberto Guarinello.

GAIA, Deivid Valério. Abundance of currency and financial crisis in Rome: legal and economic issues around interest rates at the time of Augustus and Tiberius. História, v.28, n.2, p.571-602, 2009.

\begin{abstract}
After defeating Antony and Cleopatra at Actium in 31 $\mathrm{BC}$, Octovian brought the treasury of Egypt to Rome thus providing an abundance of wealth wich contributed to stabilize both public and private finances. The value of land increased and interest rates fell. During the Augustan Principate, Roman economy went through a period of financial equilibrium. However, this balance was broken in the early 30's AD under Tiberius' Principate when, according to Tacitus, Suetonius and Dion Cassius, the first inopia nummorum (lack of liquidity) crisis of the Roman Empire came about. Based on the accounts cited above and a comparative perspective with other financial crises in the Roman Empire, this paper examines issues concerning
\end{abstract}


interest rates from the end of the Republic to the Principate, it presents an overview of cash loans and interest rates at the time of Augustus and gives my reading of the crisis of $\mathrm{AD} 33$, highlighting the main discussions about its origins, its development and its end.

Keywords: Inopia nummorum; Financial Crisis; Roman Economy; Roman Empire; Interest Rates.

\section{NOTAS}

${ }^{1}$ Este artigo é fruto da minha dissertação de mestrado, arguida em junho de 2009 sob a orientação de Jean Andreau. VALERIO GAIA, Deivid Valério, Le taux d'intérêt et ses variations dans le monde romain: $\mathrm{III}^{\mathrm{e}}$ siècle av. J.-C. - III $^{\mathrm{e}}$ siècle ap. J.-C.,(2 Vols), Paris, EHESS, 2009, (dissertação de mestrado). Já tive a oportunidade, a convite de Fábio Faversani em nome do Laboratório de estudos sobre o Império romano e da Universidade Federal de Ouro Preto, de apresentar as ideias principais deste artigo em duas diferentes palestras proferidas em julho de 2009: a primeira em Mariana - Minas Gerais (UFOP - Fábio Faversani) e a segunda em Cachoeira - Bahia (UFRB - Fábio Duarte Joly).

2 DE PRACONTAL, Michel \& WALTER, Christian, Le virus B. Crises financières et mathématiques. Le Seuil, 2009.

AGLIETTA, Michel, Crises financières et régulation monétaire, La Découverte, 1995-2005.

CHAVAGNEUX, Christian, "Banques: des risques mal calculé s ", Alternatives économiques n 283 de septembre 2009.

${ }^{3}$ Abreviações das edições das fontes antigas citadas:

App. Mithr $=$ Apiano, Mithridatica (La Guerre de Mithridate: livre XII, texte établi et traduit par P. Goukowsky, 2e tirage, Paris, Les Belles Lettres, 2003).

Cic. ad. Att.: Cícero, Epistulae ad Atticum. (Cicero's Letters to Atticus. 6 vols. ed. D. R. Shackleton Bailey, 1965-1968).

Cic. Verr.: Cícero, In Verrem. (M. Tulli Ciceronis Orationes. Vol. 3, ed. W. Peterson, 1917. / Première action contre C.Verrès - Seconde action contre C. Verrès, La Préture urbaine, Livre I, texte établi et traduit par H. de La Ville de Mirmont, Paris, Les Belles Lettres, 1922, Tome II, (2e 
ABUNDANCIA DE LIQUIDEZ E CRISE FINANCEIRA EM ROMA:...

tirage 2002). / Seconde action contre C. Verrès - La Préture de Sicile, Livre II, texte établi et traduit par H. de La Ville de Mirmont, Paris, Les Belles Lettres, 1936, Tome III, (2e édition 1960 - 2e tirage de la 2e édition 2002).

CIL: Corpus Inscriptionum Latinarum, Berlin, 1869-1933, V. 1-15.

Dig.: Digesto, Digesta Iustiniani. (The Digest of Justinian. Vols. 1-4, ed. T. Mommsen, P. Krüger, A. Watson, 1985).

Dion Cássio: Dion Cássio, Historiae Romanae (Cassii Dionis Cocceiani historiarum Romanarum quae supersunt, 3 vols., Ed. Boissevain, U.P.Berlin: Weidmann, 1:1895; 2:1898; 3:1901, Repr. 1955. / Roman History, with an English translation by E. CARY, Londres, Heinemann, 1969 (Vol. IV - The Loeb classical library). / Histoire romaine: livres 50 et 51, texte établi, trad. et annoté par Marie-Laure Freyburger et JeanMichel Roddaz, Paris, Les Belles Lettres, 1991. / Histoire romaine, trad. par E. Gros et continué par V. Boissée, Paris, Librairie de Firmon Ditot frères, 1865.)

Hor. S.: Horácio, Sermones (Q. Horati Flacci Opera, ed. F. Klingner, 1959).

Plínio. N.H.: Plínio, o Antigo, Naturalis Historia (Livre XIV, (De la nature des arbres fruitiers), texte établi, traduit et commenté par J. André, Paris, Les Belles Lettres, 1958 (2e tirage 2003) / C. Plini Secundi Naturalis Historiae Libri XXXVII. Vols. 1-5, ed. C. Mayhoff, 1892-1909).

Plut. Luc:: Plutarco, Plutarchus Biogr., Phil., Lucullus (Plutarchi vitae parallelae, vol. 1.1, 4th edn., Ed. Ziegler, K.Leipzig: Teubner, 1969./ Cimon-Lucullus. Nicias-Crassus, texte établi et traduit par R. Flacelière et E. Chambry, Paris, Les Belles Lettres,1972, Tome VII (2e tirage 2003)).

S.H.A., Anton. Pius: História Augusta, Scriptores Historiae Augustae, Antonino Pio (Scriptores Historiae Augustae. Vol. 1, ed. E. Hohl, 1965. / Histoire Auguste: Vies d'Hadrien,Aelius et Antonin, texte établi et traduit par J.-P. Callu, O. Desbordes et A. Gaden, Paris, Les Belles Lettres, 1992, Tome I ( 2e tirage 2002)).

Suet. Aug: Suetônio, De Vita Caesarum (C. Suetoni Tranquilli Opera. Vol. 1, ed. M. Ihm, 1908. / César. - Auguste, texte établi et traduit par H. Ailloud Paris, Les Belles Lettres, 1931, Tome I (8e tirage 2007)).

Suet. Tib: Suetônio, De Vita Caesarum (C. Suetoni Tranquilli Opera. Vol. 1, ed. M. Ihm, 1908. / Tibère. - Caligula. - Claude. - Néron. texte établi et traduit par H. Ailloud Paris, Les Belles Lettres, 1931, Tome II (9e tirage 2002)).

HISTÓRIA, São Paulo, 28 (2): 2009 
Tac. Ann: Tácito, Annales (Cornelii Taciti Annalium Ab Excessu Divi Augusti Libri, ed. C. D. Fisher, 1906. / Annales, Livres IV-VI, texte établi et traduit par P. Wuilleumier, Paris, Les Belles Lettres, 1975, Tome II (2e tirage revu et corrigé par H. Le Bonniec 1990 - 3e tirage 2003)).

Abreviações das revistas citadas:

$\boldsymbol{A J P h}$ : American Journal of Philology. Baltimore (Md.) : Johns Hopkins University Pr.

CCG: Cahiers du Centre Gustav-Glotz. Paris: Publications de la Sorbonne ; de Boccard.

JRS: The Journal of Roman Studies. London: Society for the Promotion of Roman Studies.

Ktèma: Ktèma: civilisations de l'Orient, de la Grèce et de Rome antiques. Strasbourg : Université Marc Bloch, Centre de Recherches sur le Proche-Orient et la Grèce antique.

MAAR: Memoirs of the American Academy in Rome

AncSoc: Ancient society. Leuven: Peeters.

${ }^{4}$ Cic. ad. Att. 5, 21, 11-13; 6, 1-5; 6, 2, 7.

${ }^{5}$ Plut. Luc. 20. et App. Mithr. 62, 63, 83.

6 Cic.ad. Att., 5 21, 13. Vide: BARLOW, Charles Thomas, Bankers, moneylenders and interest rates in the Roman Republic, Ann ArborLondres, University Microfilms International, 1978, p. 172. \& BILLETER, Gustav, Geschichte des Zinsfusses im griechisch-römischen Altertum bis auf Justinian, Leipzig, B. G. Teubner, 1898, p. 169 - 175.

${ }^{7}$ Cic. ad Att. 4, 15, 7 ; 4, 17, 3-3.

${ }^{8}$ Suet. Aug. 41, 2.

Batalha do Ácio: Em 31 a.C., a parte oriental do mundo romano era dirigida por Marco Antônio, e a parte Ocidental por Otaviano. Esta batalha foi o grande combate que os confrontou e Otaviano foi vitorioso, tornando-se, mais tarde, Augusto, o primeiro Imperador de Roma. A batalha aconteceu no dia 2 de setembro de 31 a.C., no litoral do Épiro, no largo do Golfo da Ambrácia.

${ }^{9}$ Dig. 26, 7, 47, 4 (Scaevola).

${ }^{10}$ minimae usurae : juros abaixo de $4 \%$.

${ }^{11}$ S.H.A., Anton. Pius, 2, 8.

${ }^{12}$ Plínio. N.H. 14, 56.

${ }^{13}$ CIL V, 5132.

${ }^{14} 24 \%$ : Verres na Sicilia. Cic. Verr. 3, 165-170

$48 \%$ : o empréstimo de Brutos a Salamina de Chipre.

60\% : Hor. S. 1, 2, 14. 
ABUNDANCIA DE LIOUIDEZ E CRISE FINANCEIRA EM ROMA:...

15 Jean ANDREAU, " Deux études sur les prix à Rome: les " mercuriales " et le taux d'intérêt ", in Jean ANDREAU, Pierre BRIANT et Raymond DESCAT, Économie antique, prix et formation des prix dans les économies antiques, Saint-Bertrand-de-Comminges, musée archéologique départemental, 1997 (EAHSBC, 3), p. 113.

${ }^{16}$ Giuseppe CAMODECA, L'Archivio puteolano dei Sulpicii, 1, Napoli, 1992.

17 VERBOVEN, Koenraad, "Le système financier à la fin de la République romaine ", AncSoc, 24, 1993, p. 69-98 \& VERBOVEN, Koenraad, "L'organisation des affaires financières des C. Supicii de Pouzzoles (Tabulae Pompeianae Sulpiciorum) ", CCG, 2000, XI, p. 161171.

${ }^{18}$ Não podemos de forma alguma confundir a palavra usura empregada hoje com a palavra usura utilizada pelos romanos. A "nossa" usura tem o sentido de juro superior ao estabelecido por lei ou pelo uso, agiotagem, ambição ou cobiça exacerbada, ao passo que no latim da época republicana e imperial, etimologicamente, a palavra usura designava o ato de usar, de se servir de alguma coisa. Assim os romanos diziam usura vitae, usura corporis, usura solis. Pouco a pouco, a palavra passou a designar não somente o ato de usar alguma coisa, mas a cessação por parte do proprietário a um terço do uso de alguma coisa, e mais tarde a retribuição retirada desta cessação. Por causa destas diferenças de sentido da palavra usura, eu prefiro, ao invés de falar em juro usurário, falar em juro abusivo ou exorbitante, ou melhor, em contraste à expressão latina minimae usurae, prefiro falar em magnae usurae. No direito romano a palavra usura tem o mesmo sentido que a nossa palavra "juro"; dizia-se, por exemplo, solvere usuras. A palavra usura designa, na linguagem jurídica romana, tanto a retribuição que se retira do empréstimo quanto a retribuição considerada por lei legítima.

19 Já a taxa de juro baixa aparece sempre nos documentos, para ressaltar um ato de benevolentia, amicitia, munificientia ou evergetismo.

20 BILLETER, G. Geschichte des Zinsfusses im griechisch-römischen Altertum bis auf Justinian, Leipzig, B. G. Teubner, 1898, p. 103-109 et 181.

SARTRE, Maurice, L'Orient romain : Provinces et sociétés provinciales en Méditerranée orientale d'Auguste aux Sévères (31 avant J.-C. - 235 après J.-C.), Paris, Seuil, 1991, p. 155 et 171. 
${ }^{21}$ Dig. 12, 6, 26 pr. et $13,4,2,8$ (Ulpiano) ; 19, 1, 13, 26 et $22,1,9$ pr. et 1 (Papiniano) ; 45, 1, 90 (Pomponio),

${ }^{22}$ Dig. 22, 1, 1 pr. (Papiniano).

${ }^{23}$ Essa discussão foi desenvolvida com mais detalhes na minha dissertação de mestrado. Vide: VALERIO GAIA, Deivid, Le taux d'intérêt et ses variations dans le monde romain: III siècle av. J.-C. III ${ }^{e}$ siècle ap. J.-C.,(2 Vols), Paris, EHESS, 2009, (dissertação de mestrado), p. 86 - 91.

${ }^{24} \mathrm{~A}$ fundação evergética consiste na doação de uma soma de dinheiro, terras ou imóveis que o fundador lega no seu testamento ou quando ainda está vivo. $\mathrm{O}$ bem deixado pelo fundador deve propiciar rendimentos anuais (que é o capital da fundação) para um objetivo determinado, seja este continuo ou periódico. Estes rendimentos anuais da fundação são os juros. De modo geral, as inscrições apresentam o fundador, o gerente da fundação e o beneficiário que pode ser uma coletividade ou, no caso das "fundações-reflexos", o próprio doador. Como exemplo deste tipo, cito o caso de uma fundação para manutenção do próprio túmulo do doador, que de tempo em tempo alguém derrame vinho ou deixe flores no seu monumento funerário. Às vezes, as inscrições são bem detalhadas, mas nem sempre. Estas fundações garantem a "perpetuidade" do fundador, pois algumas fundações oferecidas à coletividade permitem que: se faça uma ou mais festas por ano em memória do doador, se construa monumentos, se doe dinheiro para as famílias pobres italianas que tenham crianças, etc.

Vide: ANDREAU, Jean, "Fondations privées et rapports sociaux en Italie romaine ( $\mathrm{I}^{\mathrm{er}}$-III ${ }^{\mathrm{e}}$ siècle ap. J.-C.) ", Ktèma, 2, 1977, p. 157-209.

DUNCAN JONES, Richard, The Economy of The Roman Empire, Quantitative Studies, Cambridge University Press, 1974 (2e éd., 1982).

GAIA, Deivid Valério, Le taux d'intérêt et ses variations dans le monde romain: III ${ }^{e}$ siècle av. J.-C. - III siècle ap. J.-C.,(2 Vols), Paris, EHESS, 2009, (dissertação de mestrado), p. 92-104.

${ }^{25}$ Dion Cássio, 51, 21, 4-5.

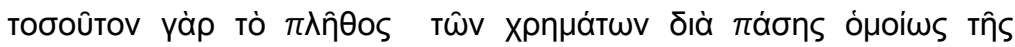

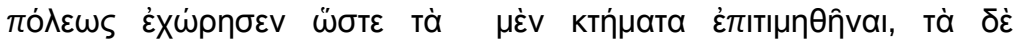

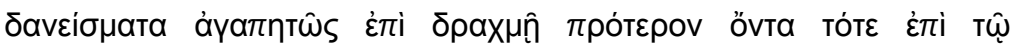


ABUNDANCIA DE LIQUIDEZ E CRISE FINANCEIRA EM ROMA:...

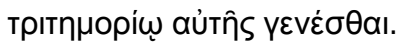

${ }^{26}$ Suet. Aug. 41, 1.

Liberalitatem omnibus ordinibus per occasiones frequenter exhibuit. nam et inuecta urbi Alexandrino triumpho regia gaza tantam copiam nummariae rei effecit, ut faenore deminuto plurimum agrorum pretiis accesserit, et postea, quotiens ex damnatorum bonis pecunia superflueret, usum eius gratuitum iis, qui cauere in duplum possent, ad certum tempus indulsit.

${ }^{27}$ Suet. Aug. 41, 1.

${ }^{28}$ Dion Cássio, 51. 21. 4 - 5.

${ }^{29}$ DION CASSIUS, Histoire romaine: livres 50 et 51, texte établi, traduit et annoté par Marie-Laure Freyburger et Jean-Michel Roddaz, Paris, Les Belles Lettres, 1991, p. 157.

${ }^{30}$ Suet. Aug. 41, 1.

${ }^{31}$ Vide : ANDREAU, Jean, Banque et affaires dans le monde romain: $I V^{e}$ J.-C. - III ${ }^{e}$ siècle ap. J.-C., Paris, Seuil, 2001, 185-204.

GAIA, Deivid Valério, Le taux d'intérêt et ses variations dans le monde romain: $I I I^{e}$ siècle av. J.-C. - III ${ }^{e}$ siècle ap. J.-C.,(2 Vols), Paris, EHESS, 2009, (dissertação de mestrado).

${ }^{32}$ Feneratores, significa todos aqueles que emprestavam dinheiro a juros independente do estatuto social. O fenerator pode ser profissional (ou seja, é especializado no empréstimo de dinheiro), o fenerator também pode ser um cavaleiro como um senador. Neste caso, seria mais difícil falar em uma especialização. Tácito escreve que quando houve as acusações contra aqueles que faziam frutificar suas fortunas pelo empréstimo de dinheiro a juros (neste caso, são os feneratores) que nenhum dos senadores se livrava de tal culpa. Tac. Ann. 6, 16.

${ }^{33}$ Suet. Aug. 39, 1

impetratis que a senatu decem adiutoribus unum quemque equitum rationem uitae reddere coegit atque in exprobratis alios poena, alios ignominia notauit, plures admonitione, sed uaria. lenissimum genus admonitionis fuit traditio coram pugillarium, quos taciti et ibidem statim legerent; notauitque aliquos, quod pecunias leuioribus usuris mutuati grauiore faenore collocassent. ac comitiis tribuniciis si deessent candidati senatores, ex equitibus $R$.

${ }^{34}$ Tac. Ann. 6, 16.

HISTÓRIA, São Paulo, 28 (2): 2009 
Interea magna vis accusatorum in eos inrupit qui pecunias faenore auctitabant adversum legem dictatoris Caesaris qua de modo credendi possidendique intra Italiam cavetur, omissam olim, quia privato usui bonum publicum postponitur. sane vetus urbi faenebre malum et seditionum discordiarumque creberrima causa eoque cohibebatur antiquis quoque et minus corruptis moribus. nam primo duodecim tabulis sanctum ne quis unciario faenore amplius exerceret, cum antea ex libidine locupletium agitaretur; dein rogatione tribunicia ad semuncias redactum, postremo vetita versura. multisque plebi scitis obviam itum fraudibus quae toties repressae miras per artes rursum oriebantur. sed tum Gracchus praetor, cui ea quaestio evenerat, multitudine periclitantium subactus rettulit ad senatum, trepidique patres (neque enim quisquam tali culpa vacuus) veniam a principe petivere; et concedente annus in posterum sexque menses dati quis secundum iussa legis rationes familiaris quisque componerent.

6, 17. Hinc inopia rei nummariae, commoto simul omnium aere alieno, et quia tot damnatis bonisque eorum divenditis signatum argentum fisco vel aerario attinebatur. ad hoc senatus praescripserat, duas quisque faenoris partis in agris per Italiam conlocaret. sed creditores in solidum appellabant nec decorum appellatis minuere fidem. ita primo concursatio et preces, dein strepere praetoris tribunal, eaque quae remedio quaesita, venditio et emptio, in contrarium mutari quia faeneratores omnem pecuniam mercandis agris condiderant. copiam vendendi secuta vilitate, quanto quis obaeratior, aegrius distrahebant, multique fortunis provolvebantur; eversio rei familiaris dignitatem ac famam praeceps dabat, donec tulit opem Caesar disposito per mensas milies sestertio factaque mutuandi copia sine usuris per triennium, si debitor populo in duplum praediis cavisset. sic refecta fides et paulatim privati quoque creditores reperti. neque emptio agrorum exercita ad formam senatus consulti, acribus, ut ferme talia, initiis, incurioso fine.

${ }^{35}$ Suet. Tib. 41, 1-3.

Publice munificentiam bis omnino exhibuit, pro posito milies sestertium gratuito in trienni tempus et rursus quibusdam dominis insularum, quae in monte Caelio deflagrarant, pretio restituto. quorum alterum magna difficultate nummaria populo auxilium 
ABUNDANCIA DE LIQUIDEZ E CRISE FINANCEIRA EM ROMA:...

flagitante coactus est facere, cum per senatus consultum sanxisset, ut faeneratores duas patrimonii partes in solo collocarent, debitores totidem aeris alieni statim soluerent, nec res expediretur; alterum ad mitigandam temporum atrocitatem. quod tamen beneficium tanti aestimauit, ut montem Caelium appellatione mutata uocari Augustum iusserit.

${ }^{36}$ Dion Cássio, 58, 21, 4 - 6.

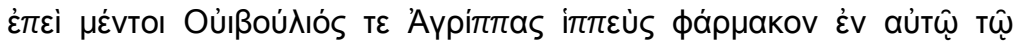

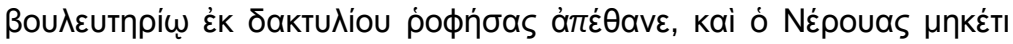

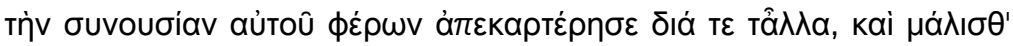

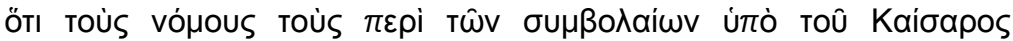

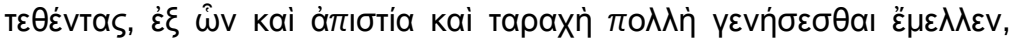

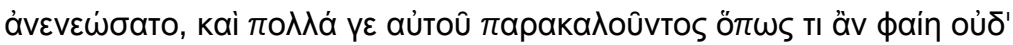

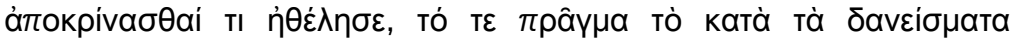

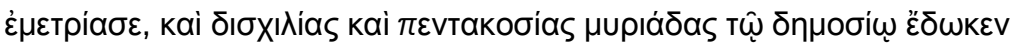

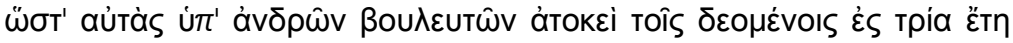

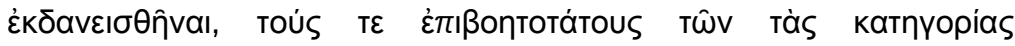

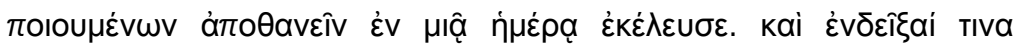

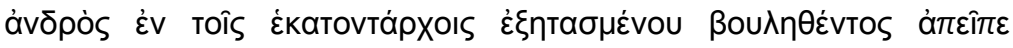

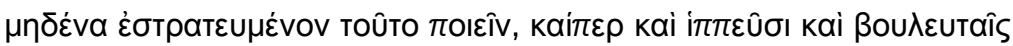

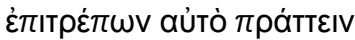

${ }^{37}$ Sabe-se que as acusações ocorreram em 33 d.C., visto que nesta época (Semprônio?) Graco era pretor. Vide GRIMAL, Pierre, "index ", in. Tacite œuvres complètes, textes traduits, présentés et annotés par Pierre Grimal, Paris, Gallimard, 1990, (Bibliothèque de la Pléiade), p.1125.

${ }^{38}$ Seriam delatores? O texto não nos prova. No entanto, André Tchernia os chama de delatores. Eu prefiro chamá-los de acusadores. TCHERNIA, André, "Remarques sur la crise de 33", in LO CASCIO, Elio (org.), Credito e moneta nel mondo romano : atti degli incontri capresi di storia dell'economia antica (Capri 12-14 ottobre 2000), Bari, Edipuglia, 2003, p. 131-146, p. 131. Mas é importante ressaltar que o Principado 
de Tibério foi época de brilho para os delatores. Tácito escreve que, quando em 21 d.C., alguém propôs frear a avidez dos delatores, Tibério se opôs, alegando que os serviços dos delatores eram importantes para o Estado. Tac. Ann. 4, 30.

${ }^{39}$ Várias edições traduzem a palavra latinan fenus, oris, n., por usura (no seu sentido contemporâneo), ou taxa de juros excessiva, particularmente a edição dos Annales de Tácito traduzida por Pierre Wuilleumier (1990). Eu não concordo com esta tradução, pois os romanos para expressarem o sentido de usura utilizavam outras palavras ou expressões como magna usura, grande fenus, graue fenus, magnus fenus, grauissima usura, maxima usura, etc. Palavra fenus (pl. fenora) e usura (pl. usurae) quando não estão acompanhadas de adjetivo, podem, entre os seus outros sentidos, significar taxa de juro, mas não taxa de juro abusiva, ou usurária como dizemos hoje.

${ }^{40}$ César tinha tomado esta medida relativa à parte mínima do patrimônio mobiliário que deveria ser investido em terras italianas. Ele tinha também tentado regulamentar as dívidas e o empréstimo, fixando a fração mínima do patrimônio susceptível de ser emprestado. Outros textos mencionam esta lei: Cic. Ad. Fam. 11, 27-8, Dion Cássio, $41,38,1$, mas pouco se sabe sobre ela.

41 BILLETER, Gustav, Geschichte des Zinsfusses im griechischrömischen Altertum bis auf Justinian, Leipzig, B. G. Teubner, 1898, p. 104.

Apesar da descoberta de novos documentos e das mudanças na forma de interpretar a economia antiga, a obra de Gustav Billeter ainda mantém sua relevância com relação aos estudos sobre as taxas de juros na Antiguidade Clássica.

42 ANDREAU, Jean, "Les intérêts des prêts dans les Tablettes de Murecine ", in Cahiers du Centre Glotz, 2000, XI, 151-159, p. 153.

${ }^{43}$ Claude NICOLET, " Les variations des prix et la " théorie quantitative de la monnaie " à Rome, de Cicéron à Pline l'Ancien ", Annales (ESC), 26, 1971, p. 1202-1227.

44 DEMOUGIN, Ségolène, L'Ordre équestre sous les Julio-claudiens, Rome, EFR, 1988, p. 119.

${ }^{45}$ Qual culpa? Emprestar dinheiro a juros ou emprestar dinheiro a juros exorbitantes? Ou não respeitar a lei de César? Em minha opinião, o texto não é claro neste sentido, porque, de toda forma, os juros podiam ser altos e não ultrapassar o limite de 12\% (centesimae usurae). Mas mesmo com juros a $12 \%$, já se tem reclamações. Embora não exista 
ABUNDANCIA DE LIQUIDEZ E CRISE FINANCEIRA EM ROMA:...

muita clareza, acredito que a culpa aqui se refere ao fato de que a lei de César não era mais respeitada. Isto me leva a acreditar que a lei limitava as taxas de juros, visto que os acusadores se mobilizam contra aqueles (feneratores) que aumetavam suas fortunas pelo empréstimo de dinheiro a juros (fenus - usura). Neste sentido, estou de acordo com Nicolet et Démougin uma vez que o texto de Tácito só faria sentido se esta lei limitasse os juros, de maneira direta ou indireta.

${ }^{46}$ Não existiam interdições legais contra o empréstimo a juros dos senadores. Temos um texto que mostra que uma vez Augusto censurou os cavaleiros que emprestavam dinheiro por juros baixos para reemprestarem por juros mais altos, como já foi mencionado. vide: Suet. Aug. 39, 1

47 DEMOUGIN, Ségolène, L'Ordre équestre sous les Julio-claudiens, Rome, EFR, 1988, p. 119.

${ }^{48}$ Parece-me que o prazo de 18 meses não foi dado aos devedores como escreve Nicolet. O prazo de 18 meses foi dado para que os senadores resolvessem o problema de forma geral. (annus in posterum sexque menses dati quis secundum iussa legis rationes familiares quisque componerent - Tac. Ann. 6, 16, 3.)

49 NICOLET, Claude, "Les variations des prix et la "théorie quantitative de la monnaie " à Rome, de Cicéron à Pline l'Ancien ", Annales (ESC), 26, 1971, 1202-1227, p. 1216-17.

${ }^{50}$ ANDREAU, Jean, La Vie financière dans le monde romain: Les métiers de manieurs d'argent (IV siècle av. J.-C.-III ${ }^{e}$ siècle ap. J.-C.), Rome, EFR, 1987, p 461.

51 TCHERNIA, André, "Remarques sur la crise de 33", in LO CASCIO, Elio (org.), Credito e moneta nel mondo romano: atti degli incontri capresi di storia dell'economia antica (Capri 12-14 ottobre 2000), Bari, Edipuglia, 2003, p. 131-146, p. 136.

${ }^{52}$ Suet. Aug. 41, 1.

${ }^{53}$ Isto também depende de como se pode interpretar a palavra "crise". Em minha opinião, no caso da inopia nummorum na época de Tibério, a crise aparece com o desaparecimento dos agentes financeiros do mercado. Mas o momento de crise é aquele marcado pela falta de dinheiro que vinha desde hà muito tempo e que levou os acusadores a se precipitarem sobre os feneratores. Neste momento, a crise já tinha eclodido, pois ela não aparece do nada, esta crise foi uma bola de neve que foi crescendo na medida em que o Estado entesourava o dinheiro que poderia estar em circulação. $O$ seu auge foi marcado pelas 
medidas públicas que só ajudaram a piorar o quadro de crise monetária e financeira.

${ }^{54}$ FRANK, T. "The financial crisis of 33 A. D.", AJPh, 56, 1935, p. 336351.

${ }^{55}$ RODEWALD, C, Money in the Age of Tiberius, Manchester University Press, 1976.

${ }^{56}$ ANDREAU, Jean, Banque et affaires dans le monde romain : IV $V^{e}$.-C. - III siècle ap. J.-C., Paris, Seuil, 2001, p. 196.

57 Vide: LO CASCIO, Elio, " resenha de Rodewald ", JRS, 68, 1978, p. 201-202.

58 Depende da fonte, acredito, como escreve Dion Cássio que foi a pedido de Tibério em virtude das acusações.

59 Tibério concedeu 18 meses para que os senadores resolvessem o caso e agissem conforme a lei. Se Tácito começa escrevendo sobre as reclamações dos acusadores contra aqueles que não respeitavam a lei, é óbvio que logo mais, no fim do texto (Tac. Ann. 6, 16, 3), Tácito se refere à mesma lei.

60 “Depuis Furneaux et surtout Tenney Frank, on admet unaniment que ce décret du Sénat ou de Tibère ne faisait que reprendre les termes de la lex de César citée plus haut par Tacite.Vide: NICOLET, Claude (1971): "Les variations des prix et la "théorie quantitative de la monnaie " à Rome, de Cicéron à Pline l'Ancien ", Annales (ESC), 26, 1202-1227, p. 1218.

61 Tac. Ann. 6, 16, 1

...adversum legem dictatoris Caesaris qua de modo credendi possidendique intra Italiam cavetur.

Tac. Ann. 6, 16, 3

... et concedente annus in posterum sexque menses dati quis secundum iussa legis rationes familiaris quisque componerent.

Tac. Ann. 6, 17, 1 ad hoc senatus praescripserat, duas quisque faenoris partis in agris per Italiam conlocaret.

Tac. Ann. 6, 17, 4

neque emptio agrorum exercita ad formam senatus consulti, acribus, ut ferme talia, initiis, incurioso fine. 
ABUNDANCIA DE LIQUIDEZ E CRISE FINANCEIRA EM ROMA:...

${ }^{62}$ NICOLET, Claude (1971): "Les variations des prix et la "théorie quantitative de la monnaie " à Rome, de Cicéron à Pline l'Ancien ", Annales (ESC), 26, 1202-1227, p. 1218.

${ }^{63}$ TCHERNIA, André, "Remarques sur la crise de 33", in LO CASCIO, Elio (org.), Credito e moneta nel mondo romano: atti degli incontri capresi di storia dell'economia antica (Capri 12-14 ottobre 2000), Bari, Edipuglia, 2003, p. 131-146, p. 133.

${ }^{64}$ Muitos traduzem esta palavra por bancos, mas aconselho a leitura de Jean Andreau sobre tal palavra e o sentido desta no texto de Tácito, como em outros textos. vide Jean ANDREAU, La Vie financière dans le monde romain: Les métiers de manieurs d'argent (IV $V^{\mathbb{e}}$ siècle av. J.-C.-III siècle ap. J.-C.), Rome, EFR, 1987, p. 461-462.

${ }^{65} \mathrm{Se}$ esta soma foi emprestada somente para aqueles que tinham contatos pessoais mais estreitos com os senadores, reforçando as relações interpessoais, que evidentemente existiam (como destacou Fábio Faversani - especialista do período Júlio-Claudiano - quando apresentei, a seu convite, esta comunicação na Universidade Federal de Ouro Preto). Estas relações pessoais pouco influenciaram para o fim da crise. No sentido em que, se o dinheiro tinha sido emprestado para todos aqueles que tinham o dobro da soma emprestada como caução ou se este dinheiro tinha sido emprestado para aqueles que tinham relações pessoais com os organizadores desta operação de crédito, o importante é saber que a crise foi remediada pela intervenção de Tibério independentemente destas relações pessoais, porque a partir do empréstimo deste dinheiro houve uma maior circulação monetária na cidade de Roma. Sendo assim, não acredito que neste caso as relações pessoais tenham sido tão importantes para o fim da crise, pois não importa para quem o dinheiro tenha sido emprestado, para amigos ou não amigos dos senadores e do imperador. O importante é a circulação deste dinheiro na cidade de Roma. Como diz o próprio Tácito, pouco a pouco mesmo os particulares emprestavam dinheiro quando a fides retornou.

${ }^{66}$ Ségolène Demougin destacou que as garantias exigidas, o dobro do valor emprestado em propriedades fundiárias, só podiam ser pedidas aos devedores que tinham conservado parte dos bens. As cauções constituídas em terras foram facilmente fornecidas pelos membros das ordens superiores, uma vez que era justamente em terras que o census era fundado. DEMOUGIN, Ségolène, L'Ordre équestre sous les Julioclaudiens, Rome, EFR, 1988, p. 122. 
DEIVID VALÉRIO GAIA

${ }^{67}$ Dion Cássio, 58, 21, 5.

${ }^{68}$ ANDREAU, Jean, Banque et affaires dans le monde romain: $I V^{e} \mathrm{~J} .-\mathrm{C} .-$ III ${ }^{e}$ siècle ap. J.-C., Paris, Seuil, 2001, p. 45.

Artigo recebido em 08/2009. Aprovado em 10/2009. 